Table 2

Mean Transition Probability of Words Preceded by FPs and of Words Not Preceded by FPs

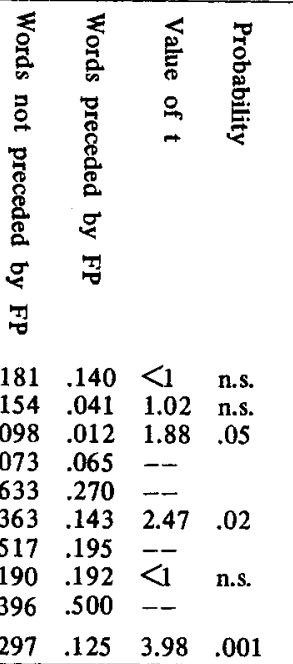

shows that the transition probability of words following FPs was lower for every part of speech except pronouns and auxiliary verbs, although the difference is not significant in every case. ( $t$ values could not be calculated in some cases, because the numbers were not large enough.)

\section{DISCUSSION}

The hypothesis has been confirmed; there is a relation between transition probability and incidence of FPs. Words preceded by FPs have a transition probability less than half that of other words. Furthermore, the relation holds for each part of speech separately, so it cannot be an artifact caused by the inclusion of some very "easy" words in the sample of words not preceded by FPs.

The only part of speech for which the relation does not hold is the pronoun. (There was only one auxiliary verb preceded by an FP in the sample.) This is interesting, inasmuch as the author has found, in unpublished research, that FPs occur significantly more often before pronouns and conjunctions than before other parts of speech. FPs that occur before pronouns and conjunctions tend to come at the beginning of a pronoun-verb sequence, i.e., at the beginning of a clause. This seemed to indicate that they occurred while the speaker was organizing his clause. Boomer (1965) reached similar conclusions on different evidence. It is particularly interesting, therefore, that the occurrence of an FP before such pronouns is apparently unrelated to the difficulty of that pronoun. This is exactly what would be expected, if indeed the speaker is pausing to organize his grammar, and not to "find" the pronoun. The relation does not hold for conjunctions, however.

The data in Table 2 also give some support for Maclay and Osgood's assump- tion that nouns, verbs, and adjectives are more "difficult" than other parts of speech, since their transition probabilities are generally lower than those of other parts of speech. Note, however, that adverbs and pronouns also have low probabilities; evidently Maclay and Osgood's method was rather crude and indiscriminating.

This study has examined the occurrence of FPs at one type of decision point, namely where the speaker is looking for a particular difficult word. It cannot be taken to prove that FPs occur at all points of difficulty, for it is quite possible they do not occur so of ten at points of grammatical or semantic decision. (Indeed, FPs do seem more frequent where the speaker is going through a list, a task that involves only finding individual words and requires no grammatical decisions.) Furthermore, there almost certainly are other ways of indicating noncompletion and continuing to produce sounds while having nothing to say, e.g., repetition or the use of various more or less meaningless words and phrases, such as "you know" or "I mean." Now that it has been established that FPs do occur at some points of difficulty, a more extensive study is required that examines the incidence of FPs in relation to individual difficult words, grammatical complexity, and difficulty of topic, and that also examines incidence of possible equivalents of FPs.
Future work should also look for a different way of estimating difficulty of individual words, since the "cloze" method is exceedingly laborious. Possibly a quicker way of estimating transitional probabilities could be found; alternatively, word frequency lists could be used.

To conclude, it does appear that FPs are related to difficulty of selection of individual words, so that the first part of Maclay and Osgood's hypothesis is at least tenable. However, much more work needs to be done to specify more precisely when FPs and their equivalents occur.

\section{REFERENCES}

BOOMER, D. S. Hesitation and grammatical encoding. Language \& Speech, 1965, 8, 148-158.

COOK, M. Anxiety, speech disturbance and speech rate. British Journal of Social \& Clinical Psychology, 1969, 8, 13-21.

GOLDMAN-EISLER, F. Psycholinguistics: Experiments in spontaneous speech. London: Academic Press, 1968.

KASL, S. V., \& MAHL, G. F. The relationship of disturbances and hesitations in spontaneous speech to anxiety. Journal of Personality \& Social Psychology, 1965, 1, 425-433.

MACLAY, H., \& OSGOOD, C. E. Hesitation phenomena in spontaneous English speech. Word, 1959, 15, 19-44.

MAHL, G. F. Disturbances and silences in the patient's speech in psychotherapy. Journal of Abnormal \& Social Psychology, 1956, 53, 1-15.

\title{
Recognition memory of preschool children for pictures and words ${ }^{1}$
}

DAVID A. CORSINI, KENNETH A.
JACOBUS, and S. DAVID LEONARD,
University of Georgia, Athens, Ga. 30601

Preshool children's memory of words and pictures was examined using a recognition-memory task. The results indicated that pictures were better retained than words. These findings were discussed in terms of previous research and theory that has dealt with children's modes of representing information.

Bruner (1964) has suggested that there are three ways by which the human organism extracts meaning from his environmental experience or represents his experience. These three means are: (a) representation on the basis of physical actions (enactive); (b) representation by imagery (ikonic); and (c) representation by symbols (symbolic). While the adult is capable of using all three means of representation, the ability to use all three is not present from birth. Bruner suggests that the preschool child is capable of using both enactive and ikonic means of representation but has only rudimentary ability to use symbolic representation. If this were correct, one consequence might be that the preschool child's capacity for storing information in memory would be better for pictures than for words.

There have been two studies with young children which at first glance appear to contradict this expectation. Ducharme \& Fraisse (1965) found that the free recall of children was less for pictures than for their concrete noun labels. Dilley \& Paivio (1968), comparing children's learning in a paired-associate task where either pictures or words were used as the response elements, found that learning was more rapid with words than with pictures.

There are at least two interpretations of these results. First, it is possible that children have a poorer capacity for storing information presented pictorially than verbally. This interpretation would run counter to Bruner's position. Second, it is 
Table 1

The Words Used in the W List

\begin{tabular}{|c|c|c|c|}
\hline Shoe & Bird & Glass & Bread \\
\hline Money & Wheel & Lion & Crown \\
\hline Cake & Dog & Moon & Chair \\
\hline Baby & Cup & Fire & Brush \\
\hline Match & Ring & Whistle & Flag \\
\hline Basket & Spoon & Tent & Sun \\
\hline Cat & Bee & Sheep & $\log$ \\
\hline Fish & Ship & Man & Bell \\
\hline Door & Branch & Horse & Nuts \\
\hline Watch & Rope & Pipe & Finger \\
\hline Hat & Box & Tie & Ballons \\
\hline Cow & Car & Nail & Tricycle \\
\hline Dress & Stairs & Star & Lamp \\
\hline
\end{tabular}

possible that children have a capacity for retention of pictorial information which is as good, or better (as suggested by Bruner's hypothesis), than their capacity to retain verbal information, but show poorer performance with pictorial stimuli because they have difficulty in producing a verbal response from the ikonic representation that they store. This possibility would suggest that when an item is presented pictorially, the young child encodes it imagistically and has difficulty in transforming or decoding this image into its verbal label.

The present study attempts to offer support for the second interpretation by demonstrating that the first interpretation is incorrect. To do this, preschool children's memory for pictures and words was examined in a recognition memory task (cf. Shepard \& Teghtsoonian, 1961). In such a task Ss are not required to produce verbal labels as a response but are asked only to indicate whether an item has or has not been previously presented. To support Bruner's hypothesis, and to question the first interpretation of the Dilley and Paivio and Ducharme and Fraisse results, it would be necessary to demonstrate that the preschool child's recognition memory for pictures was as good or better than his recognition memory for words.

\section{SUBJECTS}

A total of 40 preschool children, 20 for each recognition memory list to be described below, served as Ss. The Ss, who were predominantly white and from middle-class socioeconomic background, were obtained from two preschools in Athens, Georgia. The mean age of the children was 68.2 months (range $=52.76$ months). The mean age of children in the two conditions was 67.4 and 69.0 months for the picture and word conditions, respectively. There were approximately the same number of boys and girls in each group. Five additional Ss were eliminated from the analysis because of poor attention to the task or stereotyped responding.

\section{MATERIALS}

Two recognition memory lists were constructed, one containing pictures $(P)$ and one containing words (W). Within each list, there were 48 test items (items presented twice) and four filler items. Five, 10, 15, or 20 items occurred between the first and second presentation of a test item. Twelve test items were used at each of these intervals. Two random orders of each list were used.

The two lists, $W$ and $P$, were identical in content. Selection of items was based on the availability of pictures and the Thorndike-Lorge (1944) frequency ratings. With only three exceptions(spoon, balloon, and tricycle) the nouns were rated AA or A. The pictures were constructed by Xeroxing colored pictures commercially available from Ideal School Supply Company. The pictures were mounted on a firm backing and were $4 \times 4$ in. in size. Table 1 presents the items.

\section{PROCEDURE}

Subjects were tested individually by a young male E. Each $S$ received one of the two random orders of either the $P$ or $W$ list. The task was introduced as a remembering game in which S was to say "yes" if the picture or word was a repeat and "no" if it was a new stimulus. Before the test series of 100 items was begun, two preliminary series of six and eight items were presented to establish the appropriate responses. The pictures were presented by hand, the words presented aurally. Each item was presented immediately after $S$ had responded to the preceding item. The average time for the complete list to be presented was $5 \mathrm{~min}$ $56 \mathrm{sec}$ and $5 \mathrm{~min} 44 \mathrm{sec}$ for the $P$ and $W$ lists, respectively.

\section{RESULTS}

The results quite clearly support the expectation based on Bruner's hypothesis-significantly fewer errors were made in the picture condition than in the word condition. The mean error score in the picture condition was 2.0 (range $=0-9$ ), and in the word condition 10.9 (range $=4-22$ ). This difference was statistically significant $(\mathrm{t}=5.17, \mathrm{p}<.001)$

There were two types of errors which Ss could make: errors of omission-failure to recognize the second presentation of an item-and errors of commission-incorrect recognition of an item at its first presentation. In both the $W$ and $P$ conditions these two types of errors occurred equally often. In the word condition the mean for omission errors was 5.35 and for commission errors, 5.50. In the picture condition these scores were .95 and 1.05 , respectively.

Between the first and second presentation of a test item there were $5,10,15$, or 20 interspersed items, with 12 items at each of these intervals. Only in the word condition were there enough omission errors to examine error differences as a function of these intervals. The mean error on items recurring after 5 items $=1.6,10$ items $=1.2$, 15 items $=1.1$, and 20 items $=1.5$. Thus, there was no significant difference in omission errors as a function of the number of intervening items.

\section{DISCUSSION}

The better recognition of pictures found in this study is in accord with the theoretical position of Bruner; i.e., Ss whose dominant mode of representation is ikonic should be able to more successfully encode pictorial as opposed to verbal-symbolic information. However, it should be recognized that, even though the content is the same, pictorial and verbal stimulus information differ on several dimensions (e.g., complexity and duration of exposure). Thus, it is essentially impossible to determine whether the present results should be attributed only to the representational abilities of the Ss, only to the differences in stimulus properties present in the different modes, or to both.

In respect to the Ducharme and Fraisse and Dilley and Paivio studies, the results of the present study suggest that young children are better able to encode pictorial input but have difficulty when the task requires them to translate their ikonic representation into a verbal response. Thus, even though the young child may be better able to encode pictorial information, pictorial information will facilitate performance only when certain response opportunities are available (Corsini, in press, a, b) but will hinder performance when other responses are called for (Ducharme \& Fraisse, 1965; Dilley \& Paivio, 1968).

\section{REFERENCES}

BRUNER, J. S. The course of cognitive growth American Psychologist, 1964, 19, 1-15.

CORSINI, D. A. Developmental changes in effect of nonverbal cues on vetention. Developmental Psychology, in press, a.

CORSINI, D. A. The effect of nonverbal cues on the retention of kindergarten children. Child Development, in press, $b$.

DUCHARME, R., \& FRAISSE,P.Étude génétique de la mémorisation de mots et d'images. Canadian Journal of Psychology, 1965, 19. 253-261.

DILLEY, M. G., \& PAIVIO, A. Pictures and words as stimulus and response items in paired-associate learning of young children. Journal of Experimental Child Psychology, $1968,6,231-240$.

SHEPARD, R. N., \& TEGHTSOONIAN, M. Retention of information under conditions approaching a steady state. Journal of Experimental Psychology, 1961, 62, 302-309.

THORNDIKE, E. L., \& LORGE, I. The teacher's word book of 30,000 words. New York: Teachers College, Columbia University Press, 1944.

\section{NOTE}

1. The authors wish to thank Wayne Helms for his assistance in the collection of the data. 